Ambiente \& Água - An Interdisciplinary Journal of Applied Science
ISSN 1980-993X - doi:10.4136/1980-993X
www.ambi-agua.net
E-mail: ambi.agua@gmail.com

\title{
Evolução e desafios no gerenciamento dos resíduos sólidos urbanos no Brasil
}

\author{
doi:10.4136/ambi-agua.1635
}

Received: 27 Apr. 2015; Accepted: 27 Aug. 2015

\author{
Victor Fernandez Nascimento*; Anahi Chimini Sobral; \\ Pedro Ribeiro de Andrade; Jean Pierre Henry Balbaud Ometto \\ Instituto Nacional de Pesquisas Espaciais (INPE), São José dos Campos, SP, Brasil \\ Centro de Ciência do Sistema Terrestre (CCST) \\ *Autor correspondente: e-mail: victor.nascimento@inpe.br, \\ anahi.sobral@inpe.br, pedro.andrade@inpe.br,jean.ometto@inpe.br
}

\section{RESUMO}

A geração dos resíduos sólidos urbanos (RSU) no Brasil vem aumentando ao longo do tempo, com alterações na qualidade do resíduo, o que levanta discussões a respeito do gerenciamento e da importância em se destinar estes resíduos adequadamente. Atualmente as questões que envolvem a gestão dos RSU têm enfoque central no cumprimento de políticas públicas. A partir da implementação efetiva da Política Nacional de Resíduos Sólidos (PNRS) - lei n ${ }^{\circ}$ 12.305/2010 é que se esperam mudanças no panorama dos resíduos sólidos no Brasil. Por conta disso, este trabalho faz um levantamento bibliográfico que tem como objetivo abordar aspectos sobre os RSU no Brasil, considerando aqueles esperados para acontecer no setor público após a implementação da PNRS. Os dados apresentados e discutidos permitiram entender a evolução da gestão dos RSU no Brasil e alguns desafios para o cumprimento das determinações da PNRS, como, por exemplo, a expansão da coleta e tratamento dos RSU, o papel mais ativo da sociedade nos processos que envolvem a separação dos resíduos e a dificuldade da erradicação de lixões e sua substituição por aterros sanitários. Em geral, apesar de terem ocorrido melhoras no gerenciamento dos RSU, estas não foram suficientes para que as mudanças propostas pela PNRS fossem cumpridas e para que se estabeleça uma gestão integrada de RSU mais eficaz e sustentável tanto ao meio ambiente quanto à sociedade, denotando a emergência de soluções estruturais no setor de gerenciamentos dos RSU no Brasil.

Palavras-chaves: política nacional de resíduos sólidos, saneamento.

\section{Development and challenges in Brazilian municipal solid waste management}

\begin{abstract}
The generation of municipal solid waste (MSW) has increased over time in Brazil, along with changes in waste quality, which gives rise to discussions regarding the importance of properly managing and disposing of these wastes. Currently, issues involving the management of MSW have a central focus in carrying out public policies. Effective implementation of the National Solid Waste Policy (NSWP) - Law $\mathrm{n}^{\mathbf{o}}$. 12,305/2010 is
\end{abstract}


expected to bring changes in the panorama of solid waste in Brazil. This work is a review of literature that aims to address some aspects of the MSW in Brazil, considering some changes expected to occur in the public sector after NSWP implementation. Some data is presented and discussed in order to foster an understanding of the evolution of MSW management in Brazil and to highlight challenges for the NSWP compliance with regulation, such as the expansion of the collection and treatment of MSW, more active societal involvement in waste-separation processes and the difficulty of eradicating open dumps and replacing them with landfills. In general, while there were improvements in MSW management, they were insufficient to address the changes proposed by the NSWP in order to establish integrated MSW management that would be effective and sustainable for both the environment and society. This indicates the need for urgent change in the structure of the MSW sector in Brazil.

Keywords: national solid waste policy, sanitation.

\section{INTRODUÇÃO}

A gestão adequada dos resíduos sólidos urbanos (RSU) é um grande desafio para os países em desenvolvimento (Henry et al., 2006; Saikia e Nath, 2015). No Brasil, apesar de a sociedade ser responsável pela gestão e principalmente geração dos resíduos, ainda são os municípios os principais responsáveis pelo seu gerenciamento (Brasil, 2010).

Os resíduos sólidos são abordados em diferentes políticas públicas brasileiras, como a Política Nacional de Saneamento Básico (Lei n ${ }^{\circ} 11.445 / 2007$ ), na qual o plano municipal de resíduos sólidos deve integrar o plano municipal de saneamento e na Política Nacional de Resíduos Sólidos (PNRS) - Lei $n^{\circ}$ 12.305/2010. Entre outros aspectos, a PNRS obriga os municípios a elaborarem um Plano Municipal de Gerenciamento Integrado de Resíduos Sólidos (PMGIRS).

Com a implementação da PNRS, espera-se algumas mudanças relacionadas aos aspectos considerados importantes para a questão dos RSU no Brasil dentro do setor público e privado, envolvendo desde catadores até toda população. A Tabela 1 traz a comparação do antes e depois (esperado) da implementação desta política para alguns destes setores.

Sendo assim, neste artigo, os autores abordam algumas reflexões sobre o panorama dos resíduos sólidos no Brasil, levando em consideração o atendimento dos aspectos relacionados ao gerenciamento dos RSU esperados que acontecessem dentro do setor público após a implementação da PNRS. A qual entrou em plena vigência no final de 2014 após o encerramento do prazo de quatro anos concedidos pela lei para a implementação de uma destinação ambientalmente adequada dos resíduos sólidos urbanos em todo o país

\section{PANORAMA DOS RSU NO BRASIL}

Os resíduos sólidos podem ser classificados de acordo com a sua natureza física (seco ou molhado), composição química (orgânico ou inorgânico), periculosidade ${ }^{1}$ (Brasil, 2010; EU, 2008; Paraná, 2012; US-EPA, 2009) e origem (industrial, de saúde, da construção civil, entre outros). Neste trabalho foram abordados os resíduos conforme sua origem, focando nos resíduos sólidos urbanos que, segundo a PNRS, são formados pelos resíduos domiciliares urbanos gerados nas atividades domésticas, somados aos resíduos de limpeza urbana, gerados na varrição, limpeza de logradouros e vias públicas.

\footnotetext{
1 Resíduos perigosos, de acordo com a PNRS (Brasil, 2010), são aqueles que, em razão de suas características de inflamabilidade, corrosividade, reatividade, toxicidade, patogenicidade, carcinogenicidade, teratogenicidade e mutagenicidade, apresentam significativo risco à saúde pública ou à qualidade ambiental, de acordo com lei, regulamento ou norma técnica. Os Resíduos Não Perigosos são aqueles não enquadrados como perigosos.
}

Rev. Ambient. Água vol. 10 n. 4 Taubaté - Oct. / Dec. 2015 
Tabela 1. Comparação do Antes e Depois (esperado) da Política Nacional de Resíduos Sólidos (2010).

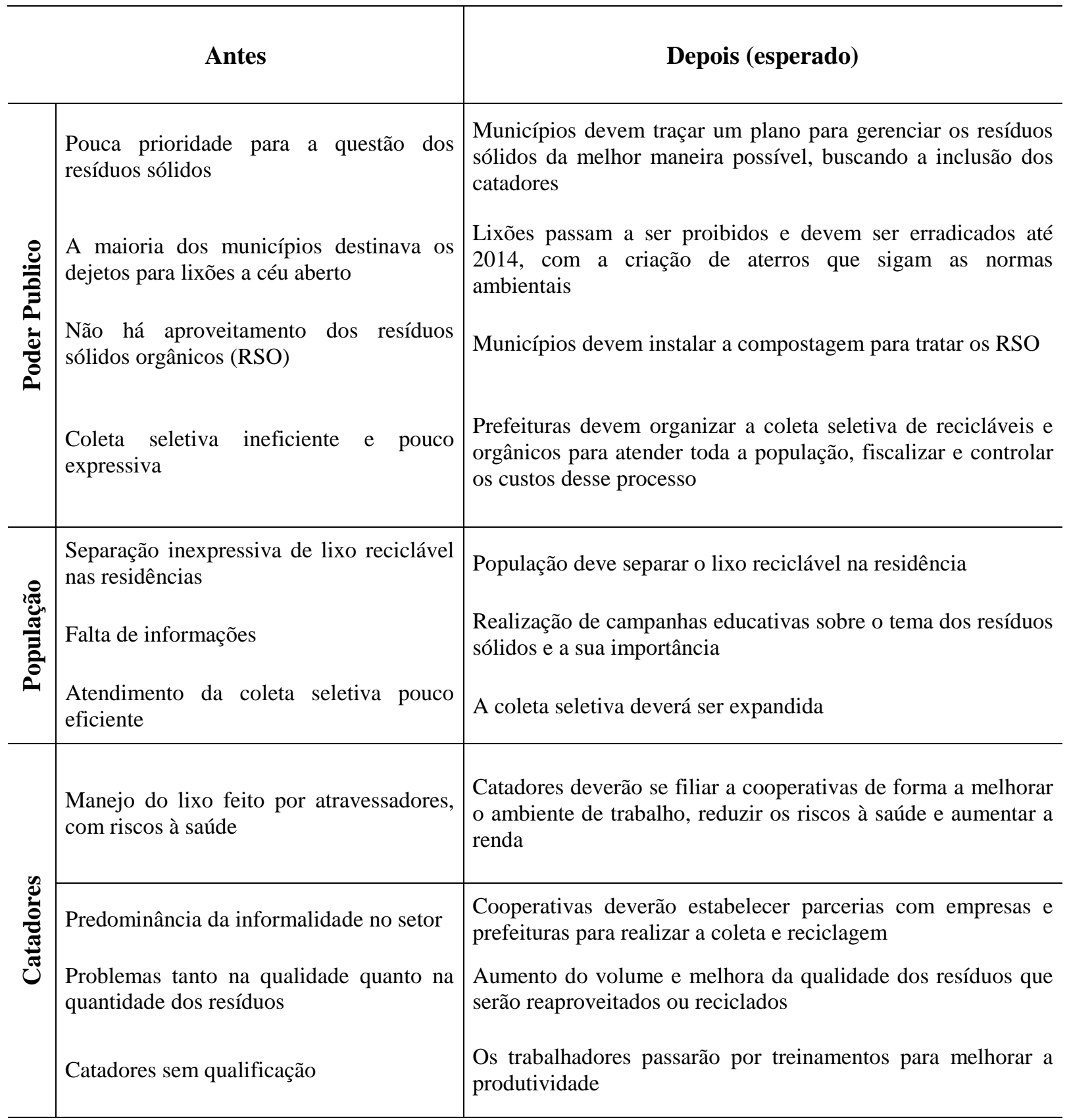

Fonte: Adaptado de CEMPRE (2013).

O Brasil vem seguindo uma hierarquia de gerenciamento dos RSU muito parecida com a de países desenvolvidos, como os da União Europeia (EU, 2008) e EUA (US-EPA, 2009). A PNRS tem como ordem de prioridade a não geração, redução, reutilização, reciclagem, tratamento dos resíduos sólidos e finalmente a disposição final dos rejeitos. Estes últimos são os resíduos sólidos que, depois de esgotadas todas as possibilidades de tratamento e recuperação por processos tecnológicos disponíveis e economicamente viáveis, não apresentam outra possibilidade que não a disposição final ambientalmente adequada (Figura 1).

As seções a seguir abordam a geração, coleta, tratamento e disposição final dos resíduos sólidos, focando o panorama dos RSU no Brasil em âmbito nacional e quando possível detalhando algumas informações a nível regional. 


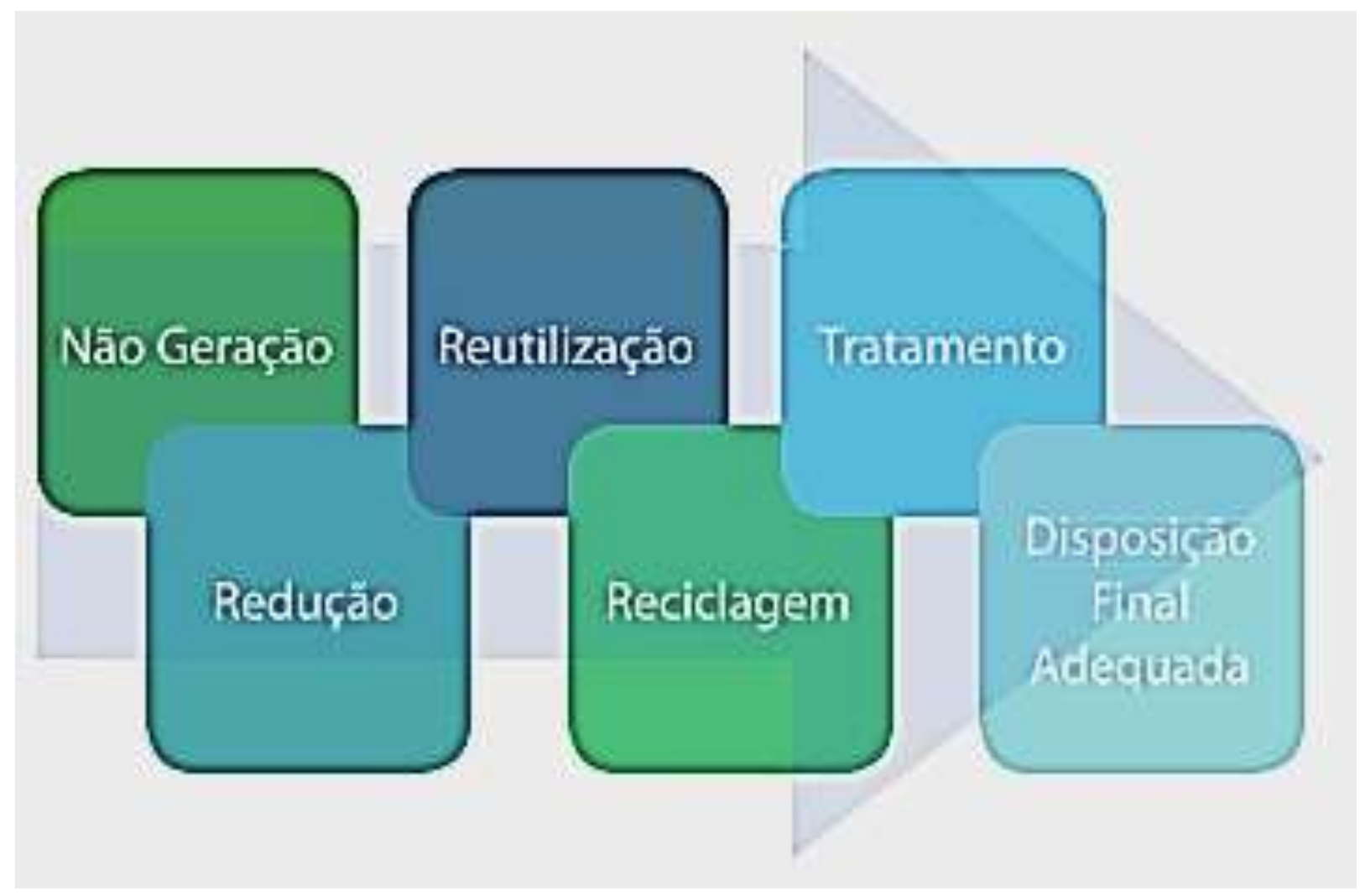

Figura 1.Ordem de prioridade no gerenciamento dos resíduos sólidos.

Fonte: Brasil e ICLEI BRASIL (2012).

\subsection{Geração de RSU}

No Brasil, é difícil quantificar os RSU gerados per capita, pois a disposição irregular, coleta informal e insuficiência do sistema de coleta pública impedem que parte dos resíduos sólidos gerados sejam coletados e contabilizados (IPEA, 2012). Cerca de 19,7\% dos resíduos gerados no Brasil não são recolhidos (CEMPRE, 2013).

Outro aspecto da geração per capita dos resíduos é que esta pode ser considerada como um marcador dos hábitos de consumo, padrão de vida, fatores culturais, renda familiar e até mesmo economia de determinada sociedade (Ojeda-Benítez et al., 2008; Suthar e Singh, 2015). Existe uma relação direta entre a produção de resíduos e a economia de um país, de forma que quanto maior a renda, maior é o consumo e, geralmente, maior é a produção de resíduos. Essa característica transforma os resíduos sólidos em importantes indicadores socioeconômicos, tanto pela quantidade de geração quanto pela sua caracterização.

Em países mais ricos, a porcentagem de recicláveis nos RSU é maior do que em de países mais pobres. Nestes, a maior parte dos resíduos é de matéria orgânica (Campos, 2012). Entretanto, este perfil vem se alterando em alguns países em desenvolvimento como, por exemplo, no Brasil, onde os resíduos ainda são predominantemente formados por matéria orgânica, mas apresentaram, nos últimos anos, um aumento porcentual significativo na geração de recicláveis (Brasil, 2012).

No ano de 2013, a população brasileira, mais de 201 milhões de habitantes, gerou 76.387.200 toneladas de RSU, sendo que a geração per capita foi, em média, 1,041 kg/hab/dia (ABRELPE, 2014). Estes valores são diferentes para cada região brasileira. Em ordem crescente de geração per capita de resíduos sólidos estão: Sul com 0,76, Norte com 0,89, Nordeste com 0,95, Centro-Oeste com 1,11, e Sudeste com 1,20 kg/hab/dia (Tabela 2). 
Tabela 2. Quantidade de RSU gerado no ano de 2013.

\begin{tabular}{lccc}
\hline Regiões & $\begin{array}{c}\text { População Total } \\
\text { (hab) }\end{array}$ & $\begin{array}{c}\text { RSU Gerado } \\
(\mathrm{t} / \mathrm{dia})\end{array}$ & $\begin{array}{c}\text { Índice } \\
(\mathrm{Kg} / \mathrm{hab} / \mathrm{dia})\end{array}$ \\
\hline Norte & 17.013 .559 & 15.169 & 0.892 \\
Nordeste & 55.794 .707 & 53.465 & 0.958 \\
Centro-Oeste & 14.993 .191 & 16.636 & 1.110 \\
Sudeste & 84.465 .570 & 102.088 & 1.209 \\
Sul & 28.795 .762 & 21.922 & 0,761 \\
Brasil & 201.062 .789 & 209.922 & 1,041 \\
\hline
\end{tabular}

Fonte: ABRELPE (2014) e IBGE (2013).

Como o Sudeste e o Nordeste são as regiões mais populosas, elas são, consequentemente, as maiores geradoras de resíduos, produzindo juntas mais de $74 \%$ de todo o RSU gerado no Brasil.

\subsection{Coleta de RSU}

Nas áreas urbanas a coleta dos resíduos alcança quase que a totalidade dos domicílios em todas as regiões brasileiras com, aproximadamente, 98,4\% de abrangência (IBGE, 2008; IPEA, 2012; Brasil, 2013). Porém, se as áreas rurais também forem consideradas, o índice de alcance da coleta de RSU diminui consideravelmente, principalmente nas regiões Nordeste e Norte, que possuem taxas de $78,22 \%$ e $80,23 \%$ respectivamente, sendo as mais baixas dentre as regiões brasileiras (Figura 2).
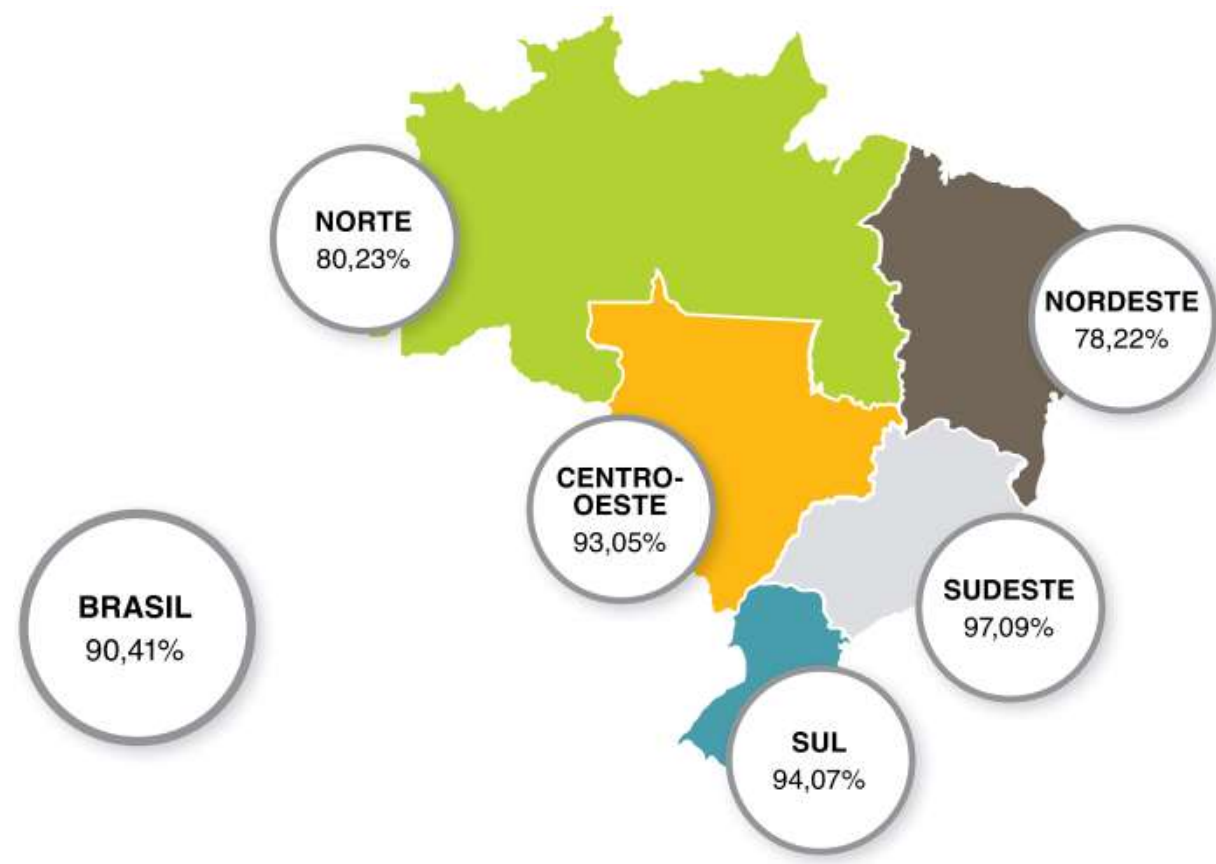

Figura 2. Índice de Abrangência do serviço de coleta de RSU segundo as regiões brasileiras.

Fonte: ABRELPE (2014). 
A coleta seletiva acontece em aproximadamente $62 \%$ dos municípios brasileiros e, somando-se todos os tipos de coletas, foram recolhidos no Brasil 69.064.935 toneladas de RSU no ano de 2013. A comparação entre a quantidade gerada e coletada mostra que diariamente mais de 20.000 toneladas deixaram de ser coletadas no país. Muito provavelmente estes resíduos tiveram um destino impróprio (ABRELPE, 2014).

\subsection{Tratamento de RSU- Reciclagem e Compostagem}

Os resíduos sólidos urbanos podem ser tratados por meio de técnicas como gaseificação, pirólise, incineração, plasma, compostagem, reciclagem e digestão anaeróbica (Marchezetti et al., 2011). Estes tratamentos apresentam algumas vantagens e desvantagens e podem ser utilizados paralelamente (IPCC, 2006).

Segundo Andrade e Ferreira (2011), independente do tratamento ou técnica a ser utilizada, é necessário realizar a caracterização da composição gravimétrica dos resíduos. No ano de 2008, a média da composição dos RSU do Brasil era formada por 31,9\% de material reciclável, $51,4 \%$ de matéria orgânica e $16,7 \%$ de outros, que são os rejeitos que não são recicláveis e materiais que são técnica ou economicamente inviáveis para a reciclagem (Brasil, 2012).

O tratamento e a gestão de resíduos sólidos urbanos devem ser observados com cautela e planejamento, principalmente devido ao impacto sobre o meio ambiente (Santibañez-Aguilar et al., 2013). Dois processos importantes para o tratamento de resíduos sólidos, reciclagem e compostagem, são salientados na literatura técnico-científica e na PNRS (Brasil, 2010). Ambos os processos envolvem a alteração de algumas propriedades físicas, químicas ou biológicas dos resíduos, com o objetivo de transformá-los em insumos ou novos produtos. Algumas vantagens e desvantagens associadas aos dois tratamentos mais comuns no Brasil são comentadas na Tabela 3.

Tabela 3. Principais vantagens e desvantagens da reciclagem e compostagem.

\begin{tabular}{|c|c|c|}
\hline \multicolumn{2}{|r|}{ Vantagem } & \multirow[b]{2}{*}{$\begin{array}{l}\text { Desvantagem } \\
\text { Para que o adubo proveniente da compostagem possa } \\
\text { ser utilizado na agricultura, é necessário que os } \\
\text { resíduos orgânicos não estejam contaminados com } \\
\text { outros materiais. Além disso, são necessários grandes } \\
\text { espaços para a implantação em grande escala e o } \\
\text { processo pode liberar odores desagradáveis se as } \\
\text { condições aeróbicas não forem mantidas, o que exige } \\
\text { uma vigilância e manutenção frequentes da pilha de } \\
\text { compostagem. Por último, pode-se dizer que no Brasil } \\
\text { este composto ainda tem uma comercialização } \\
\text { limitada. }\end{array}$} \\
\hline 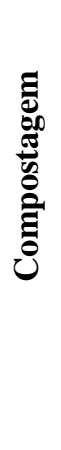 & $\begin{array}{l}\text { A prática da compostagem da matéria orgânica, } \\
\text { diminui a quantidade de resíduos que devem ser } \\
\text { depositados nos aterros sanitários, gera um } \\
\text { composto que, quando não contaminado, pode ser } \\
\text { utilizado como adubo na agricultura por ser muito } \\
\text { rico em nutrientes Além disso, este composto pode } \\
\text { melhorar a estrutura dos solos, aumentando a } \\
\text { capacidade de retenção de água e controlando } \\
\text { alguns processos erosivos. }\end{array}$ & \\
\hline 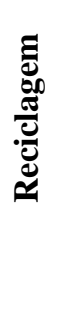 & $\begin{array}{l}\text { A prática de reciclagem, além de preservar o meio } \\
\text { ambiente através da valorização dos resíduos, } \\
\text { minimização da utilização de fontes naturais e } \\
\text { utilização mais racional dos recursos naturais, } \\
\text { também gera riqueza através da geração de } \\
\text { emprego e renda, tornando-se um componente } \\
\text { importante do processo de logística reversa. }\end{array}$ & $\begin{array}{l}\text { A coleta seletiva pode ser pouco eficiente; os } \\
\text { materiais recicláveis podem ser contaminados, } \\
\text { diminuindo seu valor comercial de venda; nem } \\
\text { sempre os materiais reciclados são mais baratos do } \\
\text { que retirar a matéria prima da natureza; pode ocorrer } \\
\text { uma baixa demanda para compra de recicláveis; e } \\
\text { pode haver a ausência de infraestrutura e incentivos } \\
\text { públicos. }\end{array}$ \\
\hline
\end{tabular}

Fonte: Modificado de Marchezetti et al. (2011).

Em 2012, foram reciclados no Brasil cerca de 26,9\% de todo o material disponível, o que representa 14.909 ton/dia de resíduos. Apesar de existir uma tendência de aumento da taxa da reciclagem, estes valores ainda são baixos (CEMPRE, 2013). Segundo Waldman (2012a;b) a 
quantidade reaproveitada dos resíduos é irrisória. Um dos poucos estudos sobre aspectos econômicos da reciclagem foi realizado pelo Instituto de Pesquisa Econômica Aplicada (IPEA), em 2010, indicando que o país perde, anualmente, cerca de R 8 bilhões ao enterrar o lixo que poderia ser reciclado.

Com a Proposta do Plano Nacional de Resíduos Sólidos e com os novos planos municipais de gerenciamento integrado de resíduos sólidos, a expectativa é o crescimento do mercado dos recicláveis no Brasil, baseado na coleta seletiva e na formação de cooperativas de catadores com investimentos público e empresarial, fundamentado principalmente na logística reversa e em outras ferramentas relacionadas à implementação da responsabilidade compartilhada pelo ciclo de vida dos produtos (Brasil, 2012).

Outro aspecto que deve ser considerado nos RSU é a reutilização da matéria orgânica. No ano de 2011, apenas 211 municípios possuíam unidades de compostagem, com destaque para os municípios dos estados de Minas Gerais e Rio Grande do Sul. Foram tratadas apenas 5\% de toda a matéria orgânica produzida no Brasil (CEMPRE, 2013). A principal dificuldade deste processo se deve à ausência da separação dos resíduos orgânicos na fonte e, consequentemente, sua contaminação, inviabilizando a reutilização do composto (IBGE, 2011).

\subsection{Disposição de RSU}

Existem no Brasil diferentes formas de disposição final de RSU, como lixões ${ }^{2}$, aterros controlados $^{3}$ e aterros sanitários. A forma mais antiga e mais utilizada é o lixão que, segundo o IBGE (2011), é a mais impactante ao meio ambiente e sociedade como um todo. Os aterros controlados também são considerados formas inadequadas de disposição final dos resíduos (ABRELPE, 2011).

Em 2008, do total de resíduos sólidos coletados nos municípios brasileiros, 50,8\% foi disposto em lixões e $22,5 \%$ em aterros controlados, conforme indicado na Tabela 4 (IBGE, 2008). Somando estas duas formas de disposição, 73,3\% dos resíduos sólidos foram dispostos de maneira inadequada.

As regiões Sul e Sudeste foram as que apresentaram menos municípios depositando resíduos em lixões $(15,8 \%$ e $18,7 \%$, respectivamente), enquanto que nas regiões Norte e Nordeste existe uma predominância dos municípios em dispor seus resíduos de forma inadequada (85,5\% e 89,3\%, respectivamente), provavelmente devido à diferença relacionada ao desenvolvimento tecnológico (IBGE, 2008).

Ainda que no ano de 2008 apenas 27,7\% dos municípios brasileiros tenham utilizando aterros sanitários para dispor os seus resíduos sólidos, segundo Jacobi e Besen (2011), houve um aumento das disposições em aterros sanitários entre 2000 e 2008. Isto provavelmente se deve ao fato de que as 13 cidades mais populosas do Brasil, cada uma com mais de um milhão de habitantes, têm seus resíduos dispostos desta maneira. Isto pode ser confirmado através dos dados levantados em 2013 pela ABRELPE (2014), nos quais 58,3\% dos resíduos coletados foram depositados em aterros sanitários, e os $41,7 \%$ restantes, que correspondem a 79 mil

\footnotetext{
2 “Lixões são áreas que recebem os resíduos sólidos em seu estado bruto sobre o terreno, sem nenhum preparo de impermeabilização e de tratamento dos efluentes líquidos derivados da decomposição do lixo, como o chorume, que por sua vez acaba infiltrando no solo, contaminando todo o lençol freático, e, consequentemente, toda a população que se utiliza desse recurso hídrico" (IBGE, 2011).

3 "Os aterros controlados são considerados uma fase intermediária entre o lixão e aterro sanitário. Sua principal característica consiste no cuidado de cobrir diariamente os resíduos sólidos com uma camada de terra ou outro tipo de material visando diminuir a incidência de animais transmissores de doenças. Esta forma de disposição de resíduos sólidos, apesar de ser considerada atualmente inadequada vem sendo cada vez mais utilizada, principalmente pelos municípios de pequeno e médio porte" (IBGE, 2011).
} 
toneladas diárias de resíduos, ainda foram encaminhados para lixões ou aterros controlados (Figura 3).

Tabela 4. Destino final dos resíduos sólidos, por unidades de destino dos resíduos no Brasil - 1989/2008.

\begin{tabular}{cccc}
\hline \multirow{2}{*}{ Ano } & \multicolumn{3}{c}{ Destino final dos resíduos sólidos em $(\%)$} \\
\cline { 2 - 4 } & Lixão & Aterro controlado & Aterro sanitário \\
\hline 1989 & 88,2 & 9,6 & 1,1 \\
2000 & 72,3 & 22,3 & 17,3 \\
2008 & 50,8 & 22,5 & 27,7 \\
\hline
\end{tabular}

Fonte: Adaptado de IBGE, Diretoria de Pesquisas, Coordenação de População e indicadores Sociais, Pesquisa Nacional de Saneamento Básico 1989/2008.

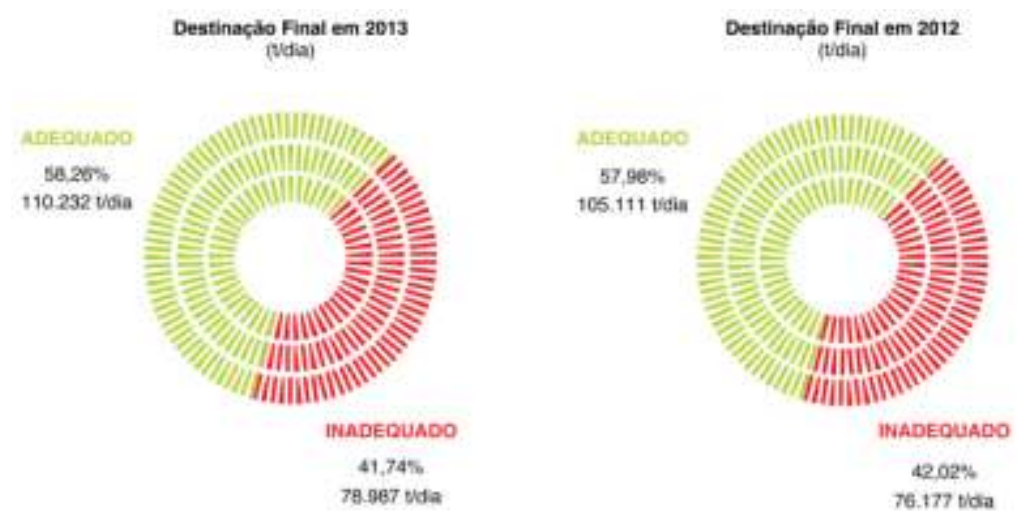

Figura 3. Destinação final dos RSU Coletados no Brasil para o ano de 2013 e 2012.

Fonte: ABRELPE (2014).

Observando a Figura 3, percebe-se que houve um aumento na quantidade e porcentagem dos RSU dispostos em aterros sanitários no Brasil, porém ainda existe uma grande quantidade de resíduos sendo disposta de maneira inadequada, podendo causar impactos negativos ao meio ambiente e a sociedade.

\section{ANÁLISE E DISCUSSÃO}

O principal objetivo do gerenciamento dos RSU é proteger a saúde da população, promover a qualidade ambiental, para desenvolver a sustentabilidade e fornecer suporte para a produtividade econômica (Karak et al., 2012). Conhecer as características da geração dos RSU é o ponto de partida fundamental para isto, porque auxilia no cumprimento da legislação e no próprio manejo e planejamento das ações de coleta, tratamento e disposição final (Campos, 2012).

As projeções demográficas para o período de 2000 a 2060 indicam que a população brasileira atingirá seu máximo em 2042, com aproximadamente 228,4 milhões de habitantes (IBGE, 2013). Se a produção per capita de resíduos for mantida na faixa do que é gerado atualmente, cerca de 1,04 kg/hab/dia, no ano de 2042 serão gerados mais de 31,6 trilhões de toneladas de RSU, computando uma geração recorde. Além disso, tem-se observado que a 
taxa de produção de resíduos per capita no país tem crescido em proporções maiores do que a taxa de crescimento da população (ABRELPE, 2014). Este fator ocasionaria valores de geração de RSU ainda maiores do que o anteriormente mencionado.

Quantificar os resíduos gerados nas áreas urbanas é dificultado pela prática da disposição irregular. Nas áreas rurais esta tarefa é ainda mais complicada, porque somado a este fator tem-se a falta ou insuficiência do sistema de coleta. Por exemplo, na região Sudeste, que é a que apresenta melhores níveis de coleta de RSU, pouco mais da metade dos domicílios rurais, aproximadamente, 50,5\%, possuem este serviço. Já na região Nordeste, existe coleta em apenas 19,8\% dos domicílios rurais, sendo este valor o mínimo nacional (IPEA, 2012). Somada toda a população que não têm este serviço de coleta de RSU no Brasil, chega-se a três milhões de pessoas, sendo que 62,4\% delas residem nas regiões do Nordeste e Norte (Brasil, 2013).

A coleta dos RSU no Brasil também está diretamente relacionada com questões econômicas porque existe um custo para que este procedimento seja realizado periodicamente. O município de São Paulo, que é o mais populoso do país, gasta em média, por ano, 627 milhões de reais com serviços de coleta. O município de São José dos Campos-SP gasta em média, por ano, 16 milhões de reais (Brasil, 2013). A despesa total com o manejo dos resíduos sólidos, quando dividida pela população urbana, resulta num valor médio anual de $\mathrm{R} \$ 86,86 / \mathrm{hab}$, sendo inferior para os municípios pequenos, cuja média é de $\mathrm{R} \$ 60,00 / \mathrm{hab}$, e superior nos municípios maiores, chegando a custar $\mathrm{R} \$ 115,16 / \mathrm{hab}$ em algumas metrópoles brasileiras (Brasil, 2013). Os custos mais atuais para as regiões brasileiras com serviço de coleta somados aos demais serviços de limpeza urbana revelam um valor médio nacional de $\mathrm{R} \$ 114,84$ por hab/ano em 2013, sendo que apenas a região Sudeste apresenta gastos mais altos do que a média, com R\$145,2 hab/ano (ABRELPE, 2014).

Em relação à coleta seletiva, apesar de $62 \%$ dos munícipios brasileiros apresentarem alguma iniciativa de coleta diferenciada para os resíduos recicláveis no ano de 2013, a maioria deles não abrangeu a totalidade do território ou da população municipal (ABRELPE, 2014). Existe, portanto, a necessidade de as prefeituras se esforçarem para buscar incentivos para ampliar o número da população atendida, levando em consideração a participação dos catadores neste processo de coleta, assim como no processo de tratamento dos resíduos. Além disso, a coleta seletiva não deve ser apenas para os recicláveis, mas também para a matéria orgânica, cabendo novamente aos órgãos públicos realizar a conscientização da população para que ocorra a separação destes resíduos nas residências, e que a participação da sociedade seja mais efetiva neste processo.

De acordo com um levantamento realizado pelo CEMPRE (2013), 80,3\% dos resíduos sólidos no Brasil são recolhidos por caminhões e levados para lixões, aterros ou reciclagem, $9,6 \%$ são queimados na propriedade, $7,2 \%$ são dispostos em caçamba, $2 \%$ são jogados em terrenos baldios ou logradouros, $0,6 \%$ são enterrados na própria propriedade, $0,2 \%$ sofrem outro tipo de destinação e $0,1 \%$ são jogados em rios, lagos ou mar. A partir destes dados, pode-se dizer que ainda existem diversos problemas ambientais relacionados aos RSU no Brasil, tanto pelos resíduos coletados que sofrem disposição final inadequada em lixões, quanto aqueles que não sofrem nenhum tipo de coleta e que são queimados ou dispostos diretamente nos recursos hídricos e no solo, podendo vir a ocasionar impactos negativos ao meio ambiente.

Segundo Dalmas et al. (2011), os custos ambientais das formas inadequadas de disposição dos RSU estão relacionados com a contaminação do solo, águas subterrâneas e atmosfera. Somado a isso, a ausência de uma política ou lei nacional relacionada aos RSU até o ano de 2010 fez com que muitos lixões e aterros controlados fossem construídos no Brasil, deixando um grande passivo ambiental (Gomes e Steinbruck, 2012). 
Segundo a PNRS (Brasil, 2010), ambos os lixões e aterros controlados deveriam ter sido eliminados até o ano de 2014, porém, mesmo com uma legislação restritiva, isso não ocorreu. Atualmente, 3.344 municípios brasileiros, $60 \%$ do total, ainda fazem uso de locais impróprios para destinação final dos resíduos coletados (ABRELPE, 2014).

Além disso, a PNRS determina que os resíduos devam ser tratados e apenas os rejeitos poderão ser dispostos em aterros sanitários. No armazenamento em aterros sanitários, os rejeitos devem ser reduzidos ao menor volume possível e devem ser seguidos princípios que reduzam impactos sociais e ambientais, tais como: impermeabilização do solo, cercamento da área, ausência de catadores e sistema de drenagem de gases, águas pluviais e lixiviado, de modo que os efluentes líquidos e gasosos do processo de decomposição dos resíduos sólidos não causem danos à saúde pública nem ao meio ambiente (ABNT, 1996; IBGE, 2008).

Em relação às questões sociais, muitas famílias que sobrevivem da coleta e venda dos materiais recicláveis retirados dos locais inadequados de disposição dos RSU não poderão mais trabalhar ali e deverão ser realocadas e organizadas em cooperativas de catadores. Segundo Tirado-Soto e Zamberlan (2013), apesar de grande parte destes catadores ainda trabalharem informalmente, existe uma tendência de criação de cooperativas por parte dos governos públicos e de organizações não governamentais.

Os sistemas de gestão de resíduos sólidos sustentáveis devem ser adotados plenamente pelas autoridades locais em colaboração com ambos os setores privado e público (Karak et al., 2012). Com a implantação da PNRS (Brasil, 2010), os municípios são obrigados a elaborar um Plano Municipal de Gerenciamento Integrado de Resíduos Sólidos para conseguir recursos federais para gerenciar os resíduos sólidos. Entretanto, segundo o IBGE (2014), apenas 33,5\% dos municípios brasileiros conseguiram entregar este plano. Como consequência, $66.5 \%$ dos municípios brasileiros não receberão recursos da união para gerenciar seus resíduos sólidos até cumprirem com esta obrigação.

\section{CONSIDERAÇÕES FINAIS}

Os dados aqui apresentados e discutidos permitem conferir o estágio de evolução da gestão de resíduos no Brasil e os desafios ainda existentes para o cumprimento das determinações da PNRS.

Em relação à geração dos RSU no Brasil, não existe uma perspectiva de diminuição do seu valor absoluto ou do seu valor per capita, contradizendo as primeiras ordens de hierarquia do gerenciamento dos resíduos sólidos propostos pela PNRS, que são não geração, redução e consequentemente a reutilização.

A coleta dos resíduos, apesar de ter um alto porcentual de abrangência nas áreas urbanas, precisa ser melhorada nas áreas rurais e nos aglomerados subnormais, onde o sistema de coleta convencional não é muito efetivo. Em relação à coleta seletiva, esta precisa ser aperfeiçoada e estudada para que se torne mais eficiente, melhorando a sua abrangência e diminuindo os custos, incentivando a participação dos catadores neste processo, bem como a participação da sociedade em separar os resíduos orgânicos e recicláveis nas suas residências.

Os tratamentos dos RSU, como a reciclagem e a compostagem, estão aumentando ano a ano, porém, com taxas de crescimento muito baixas, contradizendo o que seria esperado após a implementação da PNRS. O grande problema neste processo encontra-se na reciclagem dos materiais que não são economicamente viáveis e no tratamento da matéria orgânica, que recebe pouca atenção mesmo sendo predominante na composição dos RSU no Brasil.

Em relação à disposição final dos RSU, esperava-se que as formas inadequadas (lixões e aterros controlados) fossem encerradas até o ano de 2014 e que os resíduos estivessem predominantemente sendo enviados para os aterros sanitários, porém isto não ocorreu na maioria dos municípios brasileiros. Embora alguns prefeitos estejam começando a ser 
responsabilizados por crime ambiental, ainda não existe prazo visível para a adequação dos municípios que continuam a dispor seus resíduos de forma inadequada.

Portanto, pode-se dizer que houve uma melhora relacionada ao gerenciamento dos RSU no Brasil, mas que não foi o suficiente para que as mudanças propostas pela PNRS fossem cumpridas e para que se estabeleça uma gestão integrada de RSU mais eficaz e sustentável ao meio ambiente e a sociedade. Este fato aponta para a atual emergência de soluções estruturais para o setor de gerenciamento dos RSU no país.

\section{AGRADECIMENTOS}

À FAPESP pela bolsa de doutorado do estudante Victor Fernandez Nascimento ( $\left.\mathrm{n}^{\circ} 13 / 09039-7\right)$, aos pesquisadores Laura de Simone Borba, Silvana Amara Kampel, Plinio Carlos Alvalá, Maria Isabel Sobral Escada, Cristina Forti e Celso Von Randow do Centro de Ciência do Sistema Terrestre (CCST) e ao Instituto Nacional de Pesquisas Espaciais (INPE) pelo apoio dado durante a pesquisa.

\section{REFERÊNCIAS}

ASSOCIAÇÃO BRASILEIRA DE NORMAS TÉCNICAS - ABNT. NBR 8419: Apresentação de projetos de aterros sanitários de resíduos sólidos urbanos Procedimento. Rio de Janeiro, 1996.

ASSOCIAÇÃO BRASILEIRA DE EMPRESAS DE LIMPEZA PÚBLICA E RESÍDUOS ESPECIAIS - ABRELPE. Panorama dos resíduos sólidos no Brasil - 2010. 2011. Disponível em: http://www.abrelpe.org.br/Panorama/panorama2010.pdf. Acesso em: ago. 2015.

ASSOCIAÇÃO BRASILEIRA DE EMPRESAS DE LIMPEZA PÚBLICA E RESÍDUOS ESPECIAIS - ABRELPE. Panorama dos Resíduos Sólidos no Brasil - 2013. 2014. Disponível em: http://www.abrelpe.org.br/Panorama/panorama2013.pdf. Acesso em: ago. 2015.

ANDRADE, R. M.; FERREIRA, J. A. A Gestão de resíduos sólidos urbanos no Brasil frente às questões da globalização. Revista Eletrônica do Prodema - REDE, v. 6, n. 1, p. 7 $22,2011$.

BRASIL. Lei $\mathrm{n}^{\mathrm{O}}$ 12.305, de 2 de agosto de 2010. Institui a Política Nacional de Resíduos Sólidos; altera a Lei $\mathrm{n}^{0}$ 9.605, de 12 de fevereiro de 1998 e dá outras providências. Diário Oficial [da] União, Brasília, 03 ago. 2010.

BRASIL. Ministério das Cidades. Secretaria Nacional de Saneamento Ambiental. Lançamento Diagnóstico Resíduos sólidos 2013. 2013. Disponível em: http://www.snis.gov.br/index.php/component/content/article?id=108. Acesso em: ago. 2015.

BRASIL. Ministério do Meio Ambiente; ICLEI BRASIL. Planos de gestão de resíduos sólidos: manual de orientação - apoiando a implementação da política nacional de resíduos sólidos - do nacional ao local. 2012. Disponível em: http://www.mma.gov.br/estruturas/182/_arquivos/manual_de_residuos_solidos3003_18 2.pdf. Acesso em: ago. 2015. 
BRASIL. Proposta do plano nacional de resíduos sólidos. Brasília: Ministério do Meio Ambiente. Disponível em:

http://www.mma.gov.br/port/conama/reuniao/dir1529/PNRS_consultaspublicas.pdf.

2012. Acesso em: julho 2015.

CAMPOS, H. Renda e evolução da geração per capita de resíduos sólidos no Brasil. Engenharia Sanitária e Ambiental, v. 17, n. 2, p. 171-180, 2012. http://dx.doi.org/10.1590/S1413-41522012000200006

COMPROMISSO EMPRESARIAL PARA RECICLAGEM - CEMPRE. CEMPRE Review. 2013. Disponível em: http://cempre.org.br/artigo-publicacao/artigos. Acesso em ago. 2015 .

DALMAS, F. B. et al. Geoprocessamento aplicado à gestão de resíduos sólidos na UGRHI-11 Ribeira de Iguape e Litoral Sul. Geociências, v. 30, n. 2, p. 285-299, 2011.

EUROPEAN PARLIAMENT - EU. Directive 2008/98/EC. 2008. Disponível em: https://www.gov.uk/government/uploads/system/uploads/attachment_data/file/218586/1 _31220081122en00030030.pdf. Acesso em ago. 2015.

GOMES, E. R.; STEINBRUCK, M. A. Oportunidades e dilemas do tratamento dos resíduos sólidos no Brasil à luz da política nacional de resíduos sólidos (Lei N.12.305/2010). Confluências, v. 14, n. 1, p. 100 a 114, 2012.

HENRY, R. K.; YONGSHENG, Z.; JUN, D. Municipal solid waste management challenges in developing countries--Kenyan case study. Waste management, v. 26, n. 1, p. 92100, jan. 2006. http://dx.doi.org/10.1016/j.wasman.2005.03.007

INSTITUTO BRASILEIRO DE GEOGRAFIA E ESTATÍSTICA - IBGE. Perfil dos municípios brasileiros 2013. 2014.

Disponível em: http://cidades.ibge.gov.br/xtras/home.php. Acesso em: ago. 2015.

INSTITUTO BRASILEIRO DE GEOGRAFIA E ESTATÍSTICA - IBGE. Pesquisa nacional de saneamento básico. 2008. Disponível em:

http://www.ibge.gov.br/home/estatistica/populacao/condicaodevida/pnsb2008/PNSB_2 008.pdf. Acesso em ago. 2015.

INSTITUTO BRASILEIRO DE GEOGRAFIA E ESTATÍSTICA - IBGE. Atlas saneamento. 2011. Disponível em:

ftp://geoftp.ibge.gov.br/atlas/atlas_saneamento/atlas_saneamento_2011.zip. Acesso em: ago. 2015.

INSTITUTO BRASILEIRO DE GEOGRAFIA E ESTATÍSTICA - IBGE. Projeção da população do Brasil por sexo e idade para o período de 2000 / 2060. 2013. Disponível em:

http://www.ibge.gov.br/home/estatistica/populacao/projecao_da_populacao/2013/.

Acesso em: ago. 2015.

INTERGOVERNMENTAL PANEL ON CLIMATE CHANGE - IPCC. Waste generation, composition and management data. In: Guidelines for national greenhouse gas inventories. 2006. Disponível em: http://www.ipccnggip.iges.or.jp/public/2006gl/pdf/5_Volume5/V5_2_Ch2_Waste_Data.pdf. Acesso em: ago. 2015. 
INSTITUTO DE PESQUISA ECONÔMICA APLICADA - IPEA. Diagnóstico dos resíduos sólidos urbanos - relatório de pesquisa. 2012. Disponível em: http://www.ipea.gov.br/agencia/images/stories/PDFs/relatoriopesquisa/121009_relatorio _residuos_solidos_urbanos.pdf. Acesso em: ago. 2015.

JACOBI, P. R.; BESEN, G. R. Gestão de resíduos sólidos em São Paulo: desafios da sustentabilidade. Estudos Avançados, v. 25, n. 71, p. 135-158, 2011. http://dx.doi.org/10.1590/S0103-40142011000100010

KARAK, T.; BHAGAT, R. M.; BHATTACHARYYA, P. Municipal solid waste generation, composition, and management: The world scenario. Critical Reviews in Environmental Science and Technology, v. 42, n. 15, p. 1509-1630, ago. 2012. http://dx.doi.org/10.1080/10643389.2011.569871

MARCHEZETTI, A.; KAVISKI, E.; BRAGA, M. Aplicação do método AHP para a hierarquização das alternativas de tratamento de resíduos sólidos domiciliares. Ambiente Construído, v. 11, n. 2, p. 173-187, 2011. http://dx.doi.org/10.1590/S167886212011000200012

OJEDA-BENÍTEZ, S.; VEGA, C. A. DE; MARQUEZ-MONTENEGRO, M. Y. Household solid waste characterization by family socioeconomic profile as unit of analysis. Resources, Conservation and Recycling, v. 52, n. 7, p. 992-999, 2008. http://dx.doi.org/10.1016/j.resconrec.2008.03.004

PARANÁ. Unidades de triagem e compostagem de resíduos sólidos urbanos. 2012. Disponível em:

http://www.mpgo.mp.br/portal/arquivos/2013/06/27/15_32_13_932_apostila_rsu_mppr. pdf. Acesso em Agosto de 2015.

SAIKIA, D.; NATH, M. J. Integrated solid waste management model for developing country with special reference to Tezpur municipal area, India. International Journal of Innovative Research \& Development, v. 4, n. 2, p. 241-249, 2015.

SANTIBANEEZ-AGUILAR, J. E. et al. Optimal planning for the sustainable utilization of municipal solid waste. Waste management, v. 33, n. 12, p. 2607-22, dez. 2013. http://dx.doi.org/10.1016/j.wasman.2013.08.010

SUTHAR, S.; SINGH, P. Household solid waste generation and composition in different family size and socio-economic groups: a case study. Sustainable Cities and Society, v. 14, p. 56-63, 2015. http://dx.doi.org/10.1016/j.scs.2014.07.004

TIRADO-SOTO, M. M.; ZAMBERLAN, F. L. Networks of recyclable material wastepicker's cooperatives: an alternative for the solid waste management in the city of Rio de Janeiro. Waste management, v. 33, n. 4, p. 1004-12, abr. 2013. http://dx.doi.org/10.1016/j.wasman.2012.09.025

UNITED STATES. Environmental Protect Agency. US-EPA. Hazardous waste characteristics: a user-friendly reference document. 2009. Disponível em: http://www.epa.gov/osw/hazard/wastetypes/wasteid/char/hw-char.pdf. Acesso em: ago. 2015.

WALDMAN, M. A civilização do lixo. Revista do Instituto Humanitas Unisino, v. 410, 2012a. 
WALDMAN, M. Gestão do lixo domiciliar: considerando sobre a atuação do Estado. Texto de subsídio para a Conferência "Ecologia humana e movimentos sociais", desenvolvida no Instituto de Biociências da Universidade de São Paulo, junto à $15^{\text {a }}$ Edição da Semana Temática da Biologia USP, 02- 10-2012. São Paulo: USP, 2012B. p. 1-10 